\title{
A stimuli responsive zirconium metal-organic framework based on supermolecular design
}

Simon Krause, ${ }^{\left[{ }^{[a]}\right.}$ Volodymyr Bon, ${ }^{[a]}$ Ulrich Stoeck, ${ }^{[a]}$ Irena Senkovska, ${ }^{[a]}$ Daniel M. Többens, ${ }^{[b]}$ Dirk Wallacher, ${ }^{[c]}$ and Stefan Kaskel*[a]

[a] S. Krause, Dr. V. Bon, Dr. U. Stoeck, Dr. I. Senkovska, Prof. S. Kaskel

Department of Inorganic Chemistry

Technische Universität Dresden

Bergstr. 66, 01069 Dresden, Germany

E-mail: Stefan.Kaskel@tu-dresden.de

[b] Dr. D. M. Többens

Structure and Dynamics of Energy Materials Group,

Helmholtz-Zentrum Berlin für Materialien und Energie

Hahn-Meitner-Platz 1, 14109 Berlin, Germany

[c] Dr. D. Wallacher

Department Sample Environments

Helmholtz-Zentrum Berlin für Materialien und Energie

Hahn-Meitner-Platz 1, 14109 Berlin, Germany

Supporting information for this article is given via a link at the end of the document.

\begin{abstract}
A flexible, yet very stable metal-organic framework (DUT-98, $\mathrm{Zr}_{6} \mathrm{O}_{4}(\mathrm{OH})_{4}(\mathrm{CPCDC})_{4}\left(\mathrm{H}_{2} \mathrm{O}\right)_{4}, \mathrm{CPCDC}=9-(4-$ carboxyphenyl)-9H-carbazole-3,6-dicarboxylate) was synthesized using a rational supermolecular building block approach based on molecular modelling of metal-organic chains and subsequent virtual interlinking into a 3D MOF. Structural characterization via synchrotron single crystal X-ray diffraction (SCXRD) revealed the onedimensional pore architecture of DUT-98, envisioned in silico. After supercritical solvent extraction, distinctive responses towards various gases stimulated reversible structural transformations, as detected using coupled synchrotron diffraction and physisorption techniques. DUT-98 shows a surprisingly low water uptake but a high selectivity for pore opening towards specific gases and vapors $\left(\mathrm{N}_{2}, \mathrm{CO}_{2}, n\right.$-butane, alcohols $)$ at characteristic pressure resulting in multiple steps in the adsorption isotherm and hysteretic behavior upon desorption.
\end{abstract}


Switchability in metal-organic frameworks (MOFs) has recently been recognized as a highly promising feature providing ideal deliverable capacity in high pressure gas storage applications, ${ }^{[1]}$ high selectivity in gas separation, ${ }^{[2]}$ and sensing ${ }^{[3]}$. Pronounced changes in pore volume may even give rise to new counterintuitive phenomena. ${ }^{[4]}$ We understand "switchable MOFs" as materials undergoing a stepwise structural transformation coupled with massive changes of accessible porosity as a response to an outer stimulus such as gas or external pressure. The most prominent phenomena associated with switchability are termed "gating" and "breathing". ${ }^{[5]}$

Despite tremendous progress in the level of simulation ${ }^{[6]}$ of such phenomena, the prediction of switchability and subsequent targeted synthesis of novel flexible MOFs still remains a challenge for material chemists. ${ }^{[7]}$ Most switchable MOFs were discovered through sheer serendipity. More important, most switchable MOFs often lack thermal and chemical stability, a crucial issue especially for future industrial applications. Hence, the discovery of MIL- $53^{[8]}$ and MIL- $88^{[9]}$ by Férey and coworkers was a milestone in the field of stable and flexible MOFs. ${ }^{[10]}$ However, even the prominent MIL-53(Al), widely known as a hydrolytically fairly stable breathable MOF, decomposes after treatment in boiling water for 10 hours due to the hydrothermally unstable aluminum-oxygen bond. ${ }^{[11]} \mathrm{Zr}$-based MOFs are emerging materials with exceptional mechanical, thermal and chemical stability caused by the high connectivity of the zirconium oxo cluster as well as the very stable Zr-O bond. ${ }^{[12]}$ Recent evaluation in gas storage, ${ }^{[13]}$ separation, ${ }^{[14]}$ catalysis, ${ }^{[15]}$ and capture of toxic gases ${ }^{[16]}$ renders them as excellent candidates for adsorption applications in demanding environment. As a result, flexibility in $\mathrm{Zr-MOFs}$ has been reported rarely and was only achieved so far by introduction of flexible ligands or reduction of the connectivity of the $\mathrm{Zr}_{6}$-node by ligand substitution, which causes loss of framework stability. ${ }^{[17]}$ The targeted synthesis of a Zr-based MOF with gating transitions and a 12 -connective node for improved stability remains unexplored.

An evidentially successful route for rational MOF synthesis is the supermolecular building block (SBB) approach. ${ }^{[18]}$ In this approach zero-dimensional (OD) supermolecular building blocks (SBB) or twodimensional (2D) supermolecular building layers (SBL) are constructed from organic ligands and metal ions or clusters, the so called molecular building blocks (MBB). SBBs or SBLs can furthermore be connected either using a secondary ligand or a secondary functional group of the primary ligand to construct a 3D framework. While many MOFs have been synthesized on the basis of SBBs or SBLs, among them record holders in terms of specific surface area ${ }^{[19]}$ and storage of energy carriers ${ }^{[18]}$, the utilization of one dimensional (1D) supermolecular building chains $(\mathrm{SBC})$ is a yet rarely explored approach for the construction of MOFs.

Herein we describe the rational synthesis of the switchable Zr- based network DUT-98 (DUT - Dresden University of Technology) inspired by the wine-rack motif of MIL-53 but constructed by systematic replacement of the essential chain elements of MIL-53 by $1 \mathrm{D}$ chains of connected $\mathrm{Zr}_{6} \mathrm{O}_{4}(\mathrm{OH})_{4}(\mathrm{COO})_{12^{-}}$ clusters, the prominent motif in stable UiO-type structures. ${ }^{[20]}$ The $\mathrm{Zr}$-clusters were linked in silico by $9 \mathrm{H}$-carbazole-3,6-dicarboxylate $(\mathrm{CDC})$ into infinite $1 \mathrm{D}\left[\mathrm{Zr}_{6} \mathrm{O}_{4}(\mathrm{OH})_{4}(\mathrm{CDC})_{4}\right]^{4+} \mathrm{SBCs}$ (Fig 1a,b). CDC as a linker is characterized by an angle of $90^{\circ}$ between the planes of carboxylic groups and is well known in the synthesis of $\mathrm{SBBs}^{[21]}$ and MOFs ${ }^{[22]}$ (for details on the structural modeling see ESI). Because only eight carboxylic groups from the CDC are coordinated to each Zr-cluster, four residual coordination sites remain unoccupied. 

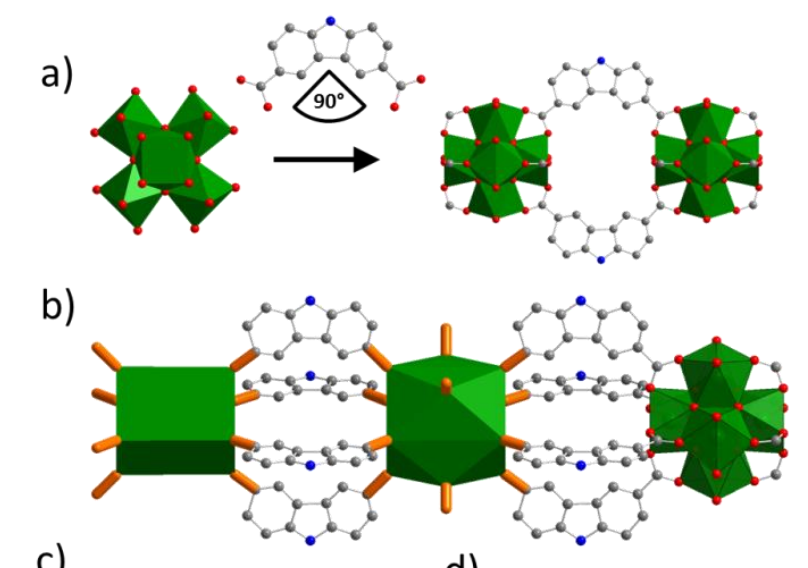

c)

d)
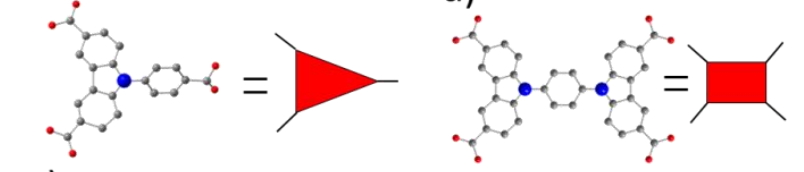

e)

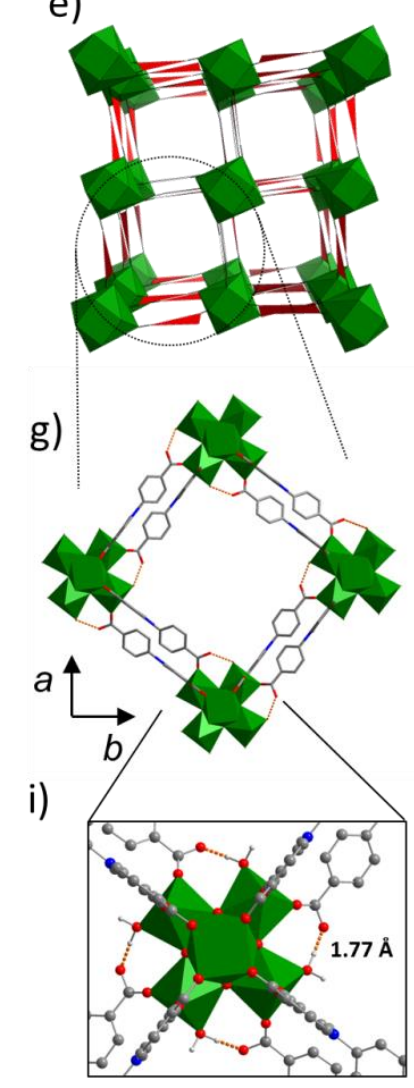

f)

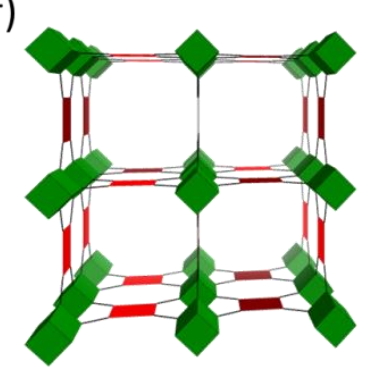

h)

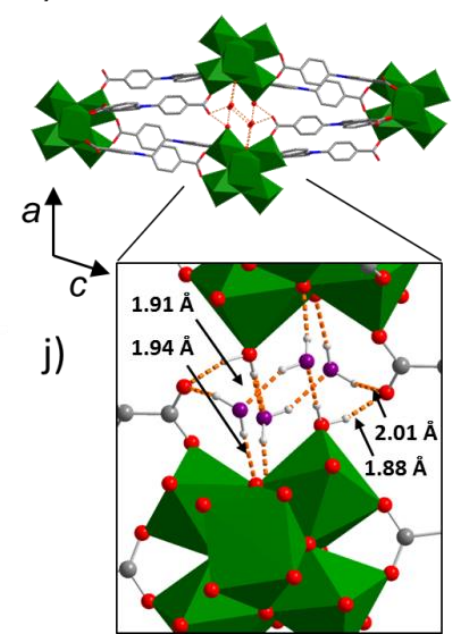

Figure 1. a) and b) Schematic representation of the formation of a $\mathrm{Zr}_{6} \mathrm{O}_{4}(\mathrm{OH})_{4}(\mathrm{COO})_{12} \mathrm{SBC}$, containing $\mathrm{CDC}$; c) 3-connecting $\mathrm{H}_{3} \mathrm{CPCDC}$ ligand; d) 4-connecting CDC-based ligand; e) (3,12)-connected framework; f) $(4,8)$-connected framework with scu topology and a channel type pore structure resulting if a 1,4-phenylene bridge is used to connect the SBCs (linker example shown in d); g) structure of DUT-98as along $c$ axis; i) cluster of DUT-98as; h) DUT-98cp along $b$ axis; j) cluster of DUT-98cp. Color code: Zr: green, C: gray, O: red, $\mathrm{N}$ : blue, $\mathrm{H}$ and $\mathrm{O}$ atoms of lattice water molecules: light gray and purple, respectively; other $\mathrm{H}$ atoms are omitted for clarity; hydrogen bonds: dotted orange lines. 
As a result, SBCs can be connected into 3D frameworks in three different ways: (i) either using the remaining open coordination sites of the clusters (Fig. 1e), or (ii) connecting two CDC nitrogen atoms in opposite SBCs (Fig. 1d), or (iii) by combination of these strategies (Fig. 1c, Fig. S20).

Zr-MOFs with multiple ligands are difficult to synthesize, ${ }^{[23]}$ hence we focused on the functionalization of the CDC ligand instead. A (4,8)-connected framework with scu topology and a channel type pore structure (Fig. 1f) was modeled using a 1,4-phenylene bridge between carbazole-nitrogen atoms (Fig. 1d, Fig. S20, S21) to connect the SBCs. However, this framework topology is known as not flexible and thus not suitable for the construction of a switchable MOF. ${ }^{[24]}$ Following route (iii), a $(3,12)$-connected network with unknown topology (Fig. 1e) was modeled attaching a terminal 4-carboxyphenyl-group to the CDC-ligand (Fig. 1c). In this case adjacent SBCs are connected in a staggered fashion and the carboxyphenyl-units coordinate to the open coordination sites of the $\mathrm{Zr}$-cluster.

Following the design strategy described above, we obtained $\mathrm{Zr}$-SBC, $\mathrm{Zr}_{6}(\mathrm{OH})_{8}(\mathrm{CDC})_{4}(\mathrm{HCOO})_{4}\left(\mathrm{CH}_{3} \mathrm{COO}\right)_{2} \cdot 2 \mathrm{DMF} \cdot 2 \mathrm{CH}_{3} \mathrm{COOH} \cdot 4 \mathrm{H}_{2} \mathrm{O}$ (DUT-80), as colorless rod shaped crystals in a solvothermal reaction of $\mathrm{H}_{2} \mathrm{CDC}$ with $\mathrm{ZrCl}_{4}$ in DMF and acetic acid as modulator. As expected, the single crystal X-ray data of DUT-80 reveal 1-D linear chains, running along [001] of the orthorhombic unit cell $(P m m n)$. In the crystal the parallel chains are slightly shifted by $0.5 c$ with respect to the repeating units to optimize dispersive interactions of the $\mathrm{Zr}$-cluster of one chain with the CDC moiety of the next chain.

Deliberately introducing a third carboxylate group yields 9-(4-carboxyphenyl)-carbazole-3,6dicarboxylic acid ( $\mathrm{H}_{3} \mathrm{CPCDC}$, Fig. $\left.1 \mathrm{C}\right)$, and enabled us to connect the DUT-80 chains into a 3D architecture in a reaction with $\mathrm{ZrCl}_{4}$ in DMF. The structure of the resulting $\left[\mathrm{Zr}_{6} \mathrm{O}_{4}(\mathrm{OH})_{4}(\mathrm{CPCDC})_{4}\left(\mathrm{H}_{2} \mathrm{O}\right)_{4}\right]$, further denoted as DUT-98as (as - as made), crystallizes in the tetragonal space group $P 4 / n$. As envisioned, the $\mathrm{Zr}_{6} \mathrm{O}_{4}(\mathrm{OH})_{4}{ }^{12+}$ nodes are connected by $4 \mathrm{CDC}$-units each, forming infinite SBCs along the [001] direction (Fig. 1g).

Each terminal phenylcarboxy-group is connected monodentate to the unoccupied coordination sites of the adjacent SBCs forming hydrogen bonds to coordinated terminal water molecules (Fig. $1 \mathrm{~g}$, i) resulting in a 3,12-connected 3D framework. 1D pore channels with a diameter of $9.8 \AA$ along the SBCs are a characteristic feature of the resulting wine-rack type framework. DUT-98 shows the expected high thermal stability up to $450^{\circ} \mathrm{C}$ (Fig. S16). Exposing the crystals to boiling water or solutions of $2 \mathrm{~N}$ $-6 \mathrm{~N} \mathrm{HCl}$ for $24 \mathrm{~h}$ gives no indication of decomposition in PXRDs (Fig. 2c) similar to MOFs based on $\mathrm{Zr}$, $\mathrm{Cr}$ and $\mathrm{Fe}^{[12 \mathrm{~d}]}$. Because solvent removal in dynamic vacuum at elevated temperatures leads to a nonporous material, (Fig. S11) a protocol involving supercritical $\mathrm{CO}_{2}$ extraction was used for desolvation under mild conditions. ${ }^{[25]}$ PXRD measurements clearly indicate a structural transition upon solvent removal from DUT-98as to DUT-98cp ( $c p$ - closed pore, Fig. S1). The crystal structure of DUT-98cp could be determined by SCXRD. Upon solvent removal a pore closing takes place accompanied by massive cell volume shrinkage of $140 \%$. Interestingly, the SBC (along [010] in DUT-98cp) remains fully intact (Fig. 1h), but a pronounced contraction of the pore structure can be observed as reflected in the change of inter-SBC distances from $24.43 \AA$ in DUT-98as to $10.63 \AA$ in DUT-98cp (Fig. $1 \mathrm{~g}, \mathrm{~h}$ ). The contraction of the structure causes a rearrangement of all hydrogen bonds between the noncoordinated carboxylate oxygen atom, the water molecules, and hydroxyl groups, coordinated to the cluster with subsequent change of the coordination mode of two carboxylates from $\mu-\mathrm{O}$ to $\mu-\mathrm{O}, \mathrm{O}^{\prime}$ (Fig. $1 \mathrm{i}, \mathrm{j}$ ). The transition is also accompanied by a slight bending of the ligand, twisting the carboxylate groups out of the carbazole plane by $7.77-21.5$ o and widening of the knee-cap angles between the carbazole carboxylate and corresponding $\mathrm{Zr}$ atoms from $0^{\circ}$ in DUT-98as structure to $20-30^{\circ}$ in DUT$98 c p$. All these rearrangements lead to the stacking of the adjacent carbazole moieties along the [010] direction, with the shortest distance approaching $4.0 \AA$. On the other hand the strained structure of 
DUT-98cp is further stabilized by intermolecular hydrogen bonds of lattice water molecules with $0 . . .0$ distances in the range of $2.72-2.83 \AA$ (Fig. 1j, Tab. S3) connecting two adjacent SBCs. Additional absorption bands in the IR spectra in the range of $3500-3650 \mathrm{~cm}^{-1}$ support this observation (Fig. S17). The formation of such a localized hydrogen bonding network is unprecedented in $\mathrm{Zr}$-MOFs and plays a crucial role in the switching transition of DUT-98.
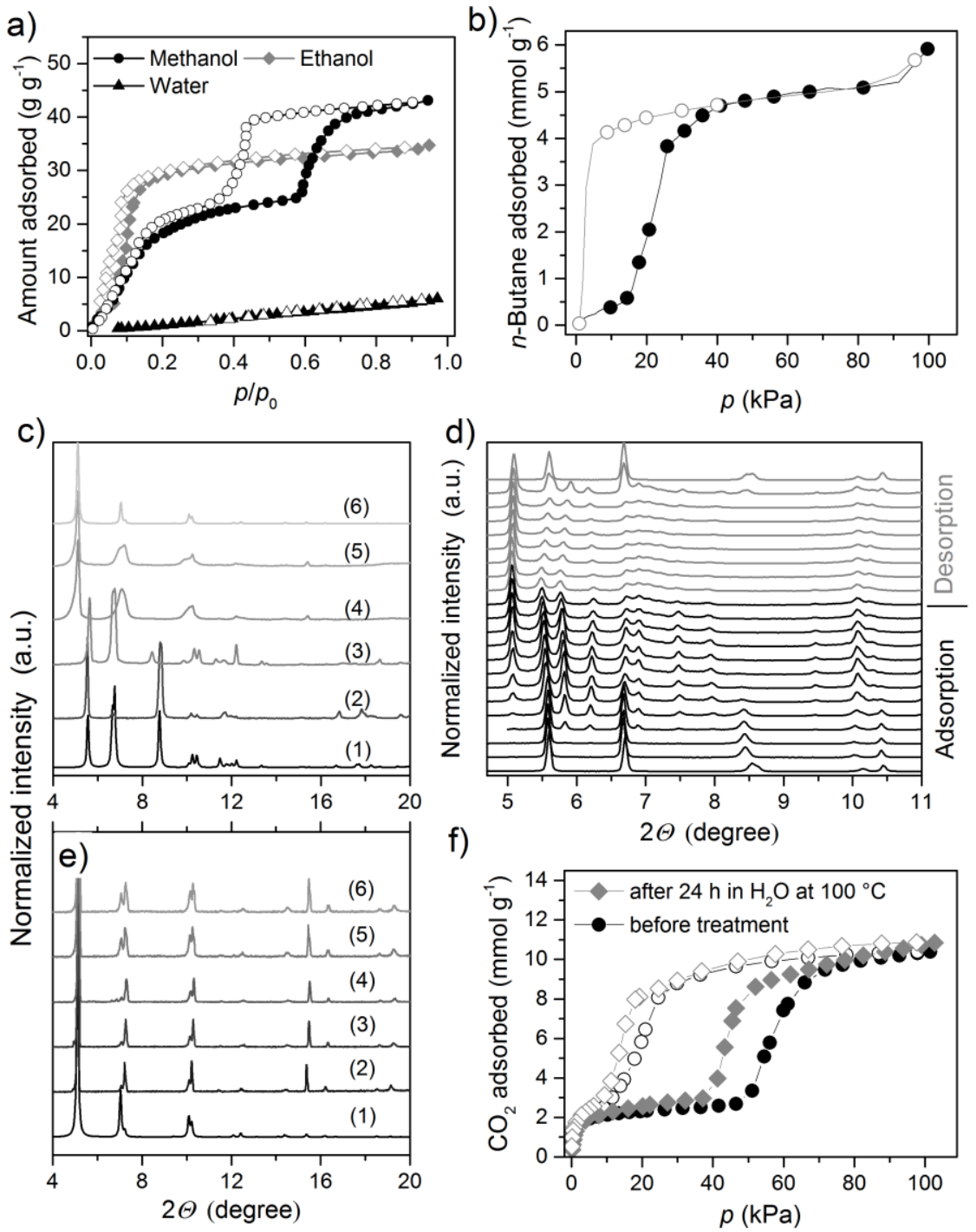

f)

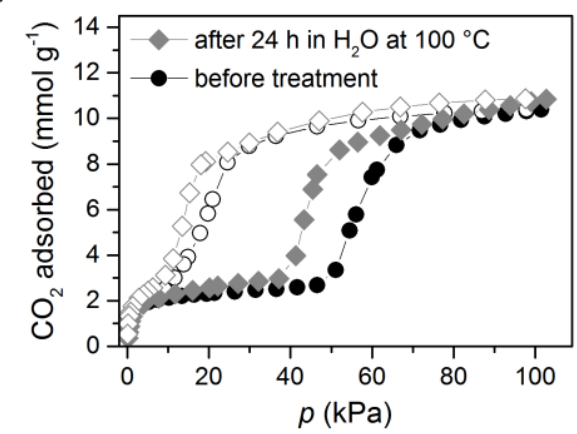

Figure 2. a) Vapor physisorption isotherms of methanol (circles), ethanol (diamonds), and water (triangles) at $298 \mathrm{~K}$; b) $n$-Butane physisorption isotherm collected during the in situ experiment; c) PXRD patterns of (1) theoretical DUT-98cp, (2) after supercritical activation, (3) suspended in water, (4) suspended in methanol, (5) suspended in ethanol at $298 \mathrm{~K}$, respectively, and (6) theoretical DUT98as; d) In situ PXRD patterns obtained during adsorption and desorption of $n$-butane at $273 \mathrm{~K}$; e) PXRD patterns of DUT-98as: theoretical pattern derived from crystal structure (1), DUT-98as in $\mathrm{H}_{2} \mathrm{O}$ for $3 \mathrm{~d}$ at $298 \mathrm{~K} \mathrm{(2),} \mathrm{DUT-98as} \mathrm{in} \mathrm{H}_{2} \mathrm{O}$ for $40 \mathrm{~d}$ at $373 \mathrm{~K} \mathrm{(3),} \mathrm{DUT-98as} \mathrm{in} 2 \mathrm{M} \mathrm{HCl}(4), 4 \mathrm{M} \mathrm{HCl}(5)$, and $6 \mathrm{M} \mathrm{HCl}$ (6) for $24 \mathrm{~h}$ at $298 \mathrm{~K}$, respectively; f) $\mathrm{CO}_{2}$ physisorption isotherms at $195 \mathrm{~K}$ : supercritically dried DUT$98 c p$ (circles); same sample suspended in water for $24 \mathrm{~h}$ at $373 \mathrm{~K}$ and subsequently supercritically dried from ethanol (diamonds). Filled symbols represent adsorption, empty symbols desorption. 
As a characteristic feature of switchable MOFs, the $\mathrm{N}_{2}$ adsorption isotherm at $77 \mathrm{~K}$ for DUT-98cp shows almost zero uptake at low relative pressures but a steep increase is observed at $p / p_{0}=0.6$ ("gate opening", Fig. S12). During desorption two steps indicate additional structural transitions, probably associated with structural transformations during the "gate closing". A similar adsorption behavior can be observed in the $n$-butane isotherm at $273 \mathrm{~K}$ with a steep increase in uptake at relative pressure around 0.2 (Fig. 2b). In contrast, $\mathrm{CO}_{2}$ adsorption at $195 \mathrm{~K}$ shows a two-step adsorption behavior with steps in the relative pressure range below 0.05 and $0.4 \leq p / p_{0} \leq 0.5$ (Fig. 2f).

To gain deeper insights into the gate opening mechanism during adsorption of $n$-butane, DUT-98cp was investigated at $273 \mathrm{~K}$ in situ by PXRD at BESSY II light-source (KMC-2 beamline) using a previously described setup. ${ }^{[26]}$ Upon adsorption of $n$-butane the formation of a novel, yet unidentified open intermediate phase is observed, which is not identical to DUT-98as (Fig. 2d, Fig. S9). DUT-98cp shows selective pore opening when it is exposed to methanol or ethanol, but the MOF remains tightly closed facing water even at high humidity level (Fig. 2a, S13).

A typical "gate opening" behavior is observed upon adsorption of $\mathrm{N}_{2}, n$-butane, $\mathrm{CO}_{2}$, methanol, ethanol, 2-propanol as well as acetone, toluene and $n$-heptane. While the adsorption isotherm of ethanol is similar to that of $n$-butane at $273 \mathrm{~K}$ with only one step, the isotherms obtained for 2propanol and methanol show two steps similar to the adsorption isotherm of $\mathrm{CO}_{2}$ at $195 \mathrm{~K}$ (Fig. 2). All isotherms show hysteretic behavior which is in particular pronounced for methanol. Only water fails to induce a structural opening in DUT-98cp indicating a high hydrophobicity of DUT-98cp. Exposing the solid towards water-methanol mixtures indicates a high selectivity for methanol-induced pore opening (ESI section 7). Such selective switching could be valuable in industrial applications involving the selective separation of alcohols from fermentation processes, or selective extraction of toxic organics such as methanol from wastewater under harsh conditions. ${ }^{[27]}$ In orienting experiments preferential methanol adsorption was indeed observed (ESI section 7). The distinctive response of DUT-98 towards vapors is a remarkable feature, implying visionary concepts in the design of valves or membranes, which open or close their pores selectively for specific molecules. The latter is reminiscent of a guard protecting an enclosed sensitive system from the environment without isolating it. Only specific molecules are allowed to pass through the channel. Integration of such selectively switchable MOFs into polymers would be an interesting approach towards mimicking biomembranes.

In conclusion we have synthesized a selectively responsive Zr-MOF (DUT-98) utilizing an original supramolecular building block approach. The structure of DUT-98 consists of 1D channels with roughly $0.9 \mathrm{~nm}$ pore diameter forming a previously unknown $(3,12)$-connected topology. DUT-98 is very robust, thermally stable and inert towards acidic medium and boiling water (Fig. 2) which makes it one of the most stable switchable MOFs known today. In situ synchrotron diffraction under controlled gas atmosphere reveals distinct and selective pore opening and closing for various gases $\left(\mathrm{N}_{2}, \mathrm{CO}_{2}\right.$ and $n$ butane) and vapors (water, alcohols). The high versatility of our proposed SBC platform providing selective recognition of vapors may be promising for the development of rational guard valve concepts for membrane integration.

\section{Experimental Section}

Crystal data for DUT-80: $\mathrm{C}_{74} \mathrm{H}_{58} \mathrm{~N}_{6} \mathrm{O}_{44} \mathrm{Zr} 6, M_{\mathrm{r}}=2282.58$, orthorhombic Pmmn, $a=17.280$ (3) $\AA, b=$ 20.570(4) $\AA, c=14.570(3) \AA, V=5178.9(18) \AA^{3}, Z=2, D_{c}=1.464 \mathrm{~g} \mathrm{~cm}^{-3}, 24189$ independent reflections observed, $R_{1}=0.0816(I>2 \sigma(I)), w R_{2}=0.3191$ (all data) and GOF $=1.091$. 
Crystal data for DUT-98as: $\mathrm{C}_{84} \mathrm{H}_{52} \mathrm{~N}_{4} \mathrm{O}_{36} \mathrm{Zr}_{6}, M_{\mathrm{r}}=2240.61$, tetragonal $P 4 / n, a=24.450$ (3) $\AA, c=$ 14.630(3) $\AA, V=8746(3) \AA^{3}, Z=2, D_{c}=0.851 \mathrm{~g} \mathrm{~cm}^{-3}, 7946$ independent reflections observed, $R_{1}=$ $0.0906(I>2 \sigma(I)), w R_{2}=0.3026$ (all data) and GOF $=1.128$.

Crystal data for DUT-98cp: $\mathrm{C}_{84} \mathrm{H}_{56} \mathrm{~N}_{4} \mathrm{O}_{38} \mathrm{Zr} \mathrm{r}_{6}, M_{\mathrm{r}}=2276.64$, triclinic $P \overline{1}, a=10.630(2) \AA, b=14.490(3) \AA$, $c=18.010(4) \AA, \alpha=111.74(3)^{\circ}, b=105.82(3)^{\circ}, \gamma=92.75(3)^{\circ}, V=2444.5(11) \AA^{3}, Z=1, D_{c}=1.547 \mathrm{~g} \mathrm{~cm}$ ${ }^{3}, 9153$ independent reflections observed, $R_{1}=0.1429(I>2 \sigma(I)), w R_{2}=0.4315$ (all data) and GOF = 1.057 .

CCDC-1556068, 1519890 and 1519891 contain the supplementary crystallographic data for DUT-80, DUT-98as and DUT-98cp. These data can be obtained free of charge from the Cambridge Crystallographic Data Centre via www.ccdc.cam.ac.uk/data request/cif. CIF files for modeled structures can be downloaded from ESI.

Acknowledgements. The authors thank the BMBF for financial support (No. 05K16OD3) and Helmholtz-Zentrum Berlin für Materialien und Energie for allocated beam time and travel funding. The authors are grateful to Sebastian Ehrling and Ulrike Koch for SEM images.

\section{References}

[1] J. A. Mason, J. Oktawiec, M. K. Taylor, M. R. Hudson, J. Rodriguez, J. E. Bachman, M. I. Gonzalez, A. Cervellino, A. Guagliardi, C. M. Brown, P. L. Llewellyn, N. Masciocchi, J. R. Long, Nature 2015, 527, 357-361.

[2] H. Sato, W. Kosaka, R. Matsuda, A. Hori, Y. Hijikata, R. V. Belosludov, S. Sakaki, M. Takata, S. Kitagawa, Science 2013.

[3] a) S. Horike, S. Shimomura, S. Kitagawa, Nat. Chem. 2009, 1, 695-704; b) G. Ferey, Dalton Trans. 2016, 45, 4073-4089.

[4] S. Krause, V. Bon, I. Senkovska, U. Stoeck, D. Wallacher, D. M. Többens, S. Zander, R. S. Pillai, G. Maurin, F. X. Coudert, S. Kaskel, Nature 2016, 532, 348-352.

[5] A. Schneemann, V. Bon, I. Schwedler, I. Senkovska, S. Kaskel, R. A. Fischer, Chem. Soc. Rev. 2014, 43, 6062-6096.

[6] a) P. G. Yot, K. Yang, F. Ragon, V. Dmitriev, T. Devic, P. Horcajada, C. Serre, G. Maurin, Dalton Trans. 2016, 45, 4283-4288; b) A. S. Munn, R. S. Pillai, S. Biswas, N. Stock, G. Maurin, R. I. Walton, Dalton Trans. 2016, 45, 4162-4168; c) A. Clearfield, Dalton Trans. 2016, 45, 4100-4112; d) L. J. Dunne, G. Manos, Dalton Trans. 2016, 45, 4213-4217; e) J. P. Durholt, R. Galvelis, R. Schmid, Dalton Trans. 2016, 45, 4370-4379.

[7] a) F.-X. Coudert, Chem. Mater. 2015, 27, 1905-1916; b) V. Bon, N. Kavoosi, I. Senkovska, P. Muller, J. Schaber, D. Wallacher, D. M. Tobbens, U. Mueller, S. Kaskel, Dalton Trans. 2016, 45, 44074415; c) A. U. Ortiz, A. Boutin, F. X. Coudert, Chem. Commun. 2014, 50, 5867-5870; d) L. Sarkisov, R. L. Martin, M. Haranczyk, B. Smit, J. Am. Chem. Soc. 2014, 136, 2228-2231. 
[8] a) K. Barthelet, J. Marrot, D. Riou, G. Férey, Angew. Chem. Int. Ed. 2002, 41, 281-284; b) C. Serre, F. Millange, C. Thouvenot, M. Noguès, G. Marsolier, D. Louër, G. Férey, J. Am. Chem. Soc. 2002, $124,13519-13526$.

[9] C. Mellot-Draznieks, C. Serre, S. Surblé, N. Audebrand, G. Férey, J. Am. Chem. Soc. 2005, 127, 16273-16278.

[10] a) G. Ferey, Chem. Soc. Rev. 2008, 37, 191-214; b) G. Ferey, C. Serre, T. Devic, G. Maurin, H. Jobic, P. L. Llewellyn, G. De Weireld, A. Vimont, M. Daturi, J.-S. Chang, Chem. Soc. Rev. 2011, 40, 550562.

[11] a) X. Qian, B. Yadian, R. Wu, Y. Long, K. Zhou, B. Zhu, Y. Huang, Int. J. Hydrogen Energy 2013, 38, 16710-16715; b) I. Bezverkhyy, G. Ortiz, G. Chaplais, C. Marichal, G. Weber, J.-P. Bellat, Microporous Mesoporous Mater. 2014, 183, 156-161.

[12] a) J. E. Mondloch, M. J. Katz, N. Planas, D. Semrouni, L. Gagliardi, J. T. Hupp, O. K. Farha, Chem. Commun. 2014, 50, 8944-8946; b) J. B. DeCoste, G. W. Peterson, H. Jasuja, T. G. Glover, Y.-g. Huang, K. S. Walton, J. Mater. Chem. A 2013, 1, 5642; c) A. J. Howarth, Y. Liu, P. Li, Z. Li, T. C. Wang, J. T. Hupp, O. K. Farha, Nat. Rev. Mater. 2016, 1, 15018; d) T. Devic, C. Serre, Chem. Soc. Rev. 2014, 43, 6097-6115.

[13] a) J. H. Cavka, C. A. Grande, G. Mondino, R. Blom, Ind. Eng. Chem. Res. 2014, 53, 1550015507; b) D. A. Gomez-Gualdron, O. V. Gutov, V. Krungleviciute, B. Borah, J. E. Mondloch, J. T. Hupp, T. Yildirim, O. K. Farha, R. Q. Snurr, Chem. Mater. 2014, 26, 5632-5639.

[14] a) D. H. Hong, M. P. Suh, Chem. Eur. J. 2014, 20, 426-434; b) Z. Hu, M. Khurana, Y. H. Seah, M. Zhang, Z. Guo, D. Zhao, Chem. Eng. Sci. 2015, 124, 61-69.

[15] D. Feng, Z. Y. Gu, J. R. Li, H. L. Jiang, Z. Wei, H. C. Zhou, Angew. Chem. Int. Ed. 2012, 51, 10307-10310.

[16] a) M. J. Katz, A. J. Howarth, P. Z. Moghadam, J. B. DeCoste, R. Q. Snurr, J. T. Hupp, O. K. Farha, Dalton Trans. 2016, 45, 4150-4153; b) G. Nickerl, M. Leistner, S. Helten, V. Bon, I. Senkovska, S. Kaskel, Inorg. Chem. Front. 2014, 1, 325; c) A. M. Ebrahim, T. J. Bandosz, ACS Appl Mater. Interfaces 2013, 5, 10565-10573.

[17] a) P. Deria, D. A. Gomez-Gualdron, W. Bury, H. T. Schaef, T. C. Wang, P. K. Thallapally, A. A. Sarjeant, R. Q. Snurr, J. T. Hupp, O. K. Farha, J. Am. Chem. Soc. 2015, 137, 13183-13190; b) B. Bueken, F. Vermoortele, M. J. Cliffe, M. T. Wharmby, D. Foucher, J. Wieme, L. Vanduyfhuys, C. Martineau, N. Stock, F. Taulelle, V. Van Speybroeck, A. L. Goodwin, D. De Vos, Chem. Eur. J. 2016, 22, 3264-3267; c) C. X. Chen, Z. Wei, J. J. Jiang, Y. Z. Fan, S. P. Zheng, C. C. Cao, Y. H. Li, D. Fenske, C. Y. Su, Angew. Chem. Int. Ed. 2016, 55, 9932-9936.

[18] U. Stoeck, S. Krause, V. Bon, I. Senkovska, S. Kaskel, Chem. Commun. 2012, 48, 10841-10843.

[19] O. K. Farha, I. Eryazici, N. C. Jeong, B. G. Hauser, C. E. Wilmer, A. A. Sarjeant, R. Q. Snurr, S. T. Nguyen, A. O. Yazaydin, J. T. Hupp, J. Am. Chem. Soc. 2012, 134, 15016-15021.

[20] F. A. A. Paz, J. Klinowski, Chem. Commun. 2003, 1484-1485.

[21] a) K. M. Thomas, Dalton Trans. 2009, 1487-1505; b) J. R. Li, H. C. Zhou, Nat. Chem. 2010, 2, 893-898; c) J. R. Li, H. C. Zhou, Angew. Chem. Int. Ed. 2009, 48, 8465-8468; d) J. R. Li, D. J. Timmons, H. C. Zhou, J. Am. Chem. Soc. 2009, 131, 6368-6369. 
[22] a) U. Stoeck, I. Senkovska, V. Bon, S. Krause, S. Kaskel, Chem. Commun. 2015, 51, 1046-1049; b) W. Lu, D. Yuan, T. A. Makal, J. R. Li, H. C. Zhou, Angew. Chem. Int. Ed. 2012, 51, 1580-1584.

[23] a) S. Yuan, J. S. Qin, L. Zou, Y. P. Chen, X. Wang, Q. Zhang, H. C. Zhou, J. Am. Chem. Soc. 2016, 138, 6636-6642; b) S. Yuan, W. Lu, Y. P. Chen, Q. Zhang, T. F. Liu, D. Feng, X. Wang, J. Qin, H. C. Zhou, J. Am. Chem. Soc. 2015, 137, 3177-3180.

[24] a) Z. J. Lin, Y. B. Huang, T. F. Liu, X. Y. Li, R. Cao, Inorg. Chem. 2013, 52, 3127-3132; b) Y.-S. Xue, Y. He, S.-B. Ren, Y. Yue, L. Zhou, Y.-Z. Li, H.-B. Du, X.-Z. You, B. Chen, J. Mater. Chem. 2012, 22, 10195; c) D. J. Mihalcik, T. Zhang, L. Ma, W. Lin, Inorg. Chem. 2012, 51, 2503-2508; d) Z.-J. Lin, T.-F. Liu, X.-L. Zhao, J. Lü, R. Cao, Cryst. Growth Des. 2011, 11, 4284-4287.

[25] R. Grünker, V. Bon, P. Muller, U. Stoeck, S. Krause, U. Mueller, I. Senkovska, S. Kaskel, Chem. Commun. 2014, 50, 3450-3452.

[26] V. Bon, I. Senkovska, D. Wallacher, A. Heerwig, N. Klein, I. Zizak, R. Feyerherm, E. Dudzik, S. Kaskel, Microporous Mesoporous Mater. 2014, 188, 190-195.

[27] B. Van de Voorde, B. Bueken, J. Denayer, D. De Vos, Chem. Soc. Rev. 2014, 43, 5766-5788. 